\title{
Successful Treatment by Argon Plasma Coagulation of Bleeding Radiation-Induced Gastroduodenal Vasculopathy
}

Gastroduodenal vasculopathy is a rare but well-known complication of upper gastrointestinal radiation treatment [1]. Although argon plasma coagulation (APC) has been shown to be effective and safe in the management of radiation-induced rectal bleeding [2] and watermelon stomach [3], the use of APC has not been reported for diffuse radiation vascular lesions located in the upper gastrointestinal tract.

In 1999, an 80-year-old man was treated for a cholangiocarcinoma by endoscopic biliary metal stenting and external radiotherapy. At 6 months later he presented with repeated episodes of upper gastrointestinal bleeding related to gastric antral and duodenal radiation-induced mucosal vascular lesions, which had not been observed at the first endoscopy prior to radiotherapy. Iron supplementation and treatment with a proton pump inhibitor had little effect on the hemorrhage so that a total of 20 packed red blood cell units were transfused during a 5-month period. When he was admitted to our unit the endoscopic examination initially showed multiple telangiectasias bleeding spontaneously in the antrum and duodenum (Figure 1). He was treated on a monthly basis by endoscopic APC ( $55 \mathrm{~W} ; 0.6$ l/min) under general anesthesia. At the first three sessions an end-viewing endoscope was used. At the fourth session a side-viewing

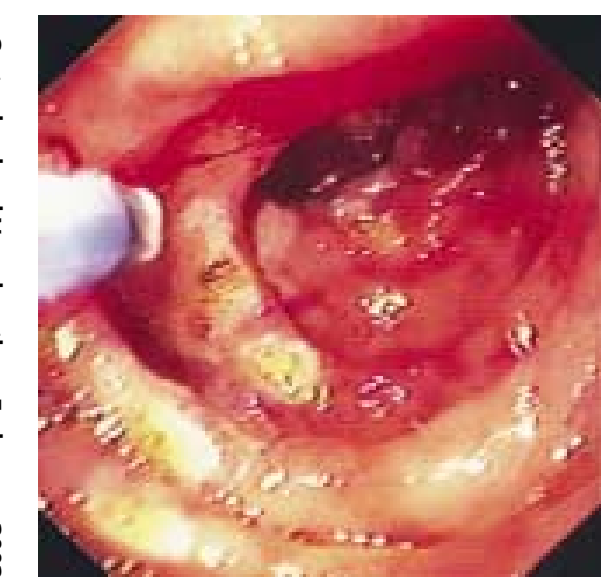

Figure 1 First use of argon plasma coagulation (APC) on spontaneously bleeding duodenal lesions endoscope was used, in order to better visualize and treat the lesions of the second duodenum, in particular those close to the biliary stent. This final procedure showed that most of the initial lesions had been eradicated (Figure $\mathbf{2}$ ), and replaced in several areas by fibrotic scars. The need for transfusions decreased progressively during treatment. No transfusions were required during the following 12-month period and a hemoglobin concentration of $10 \mathrm{~g} / \mathrm{dl}$ was sustained without any iron supplementation. The patient regained adequate independence and quality of life, and no immediate or delayed complications were observed.

The development of new indications for upper gastrointestinal radiotherapy in digestive oncology, and more specifically in the treatment of cholangiocarcinoma, is likely to lead to an increased incidence of upper digestive bleeding caused by radiation-induced gastroduodenal vasculopathy. Different methods have been proposed to achieve hemostasis of radiationinduced mucosal lesions, including surgery (partial or total gastrectomy), endoscopy (Nd:YAG laser, bipolar electrocoagulation), and interventional radiology (embolization). To our knowledge, the efficacy of APC in this location has not been reported, except for a case of radiation-induced carditis after radiotherapy for lung cancer [4]. In our patient we found regression of

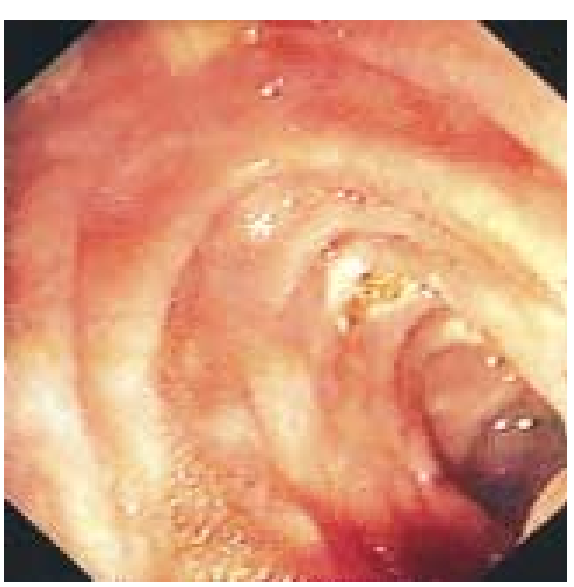

Figure 2 Endoscopic view of duodenum showing disappearance of radiation-induced mucosal lesions after APC treatment the gastroduodenal lesions seen at endoscopy, a discontinuation of blood transfusions from the fourth session onwards and during a 12-month follow-up, and a return to normal activities. The presence of the metal biliary stent in the duodenal lumen did not hinder the therapeutic procedure, nor did it lead to any specific complication. Unlike the cases of rectal stricture reported in some series involving radiation proctitis treated by APC, we did not observe duodenal stricture in this case.

\section{S. Corbinais, L. Garin, M. Pagenault, J. F. Bretagne \\ Department of Gastroenterology, CHRU Pontchaillou, Rennes, France}

\section{References}

${ }^{1}$ Vallis KA, Benjamin IS, Munro AJ et al. External beam and intraluminal radiotherapy for locally advanced bile duct cancer: role and tolerability. Radiother Oncol 1996; 41: 61 - 66

${ }^{2}$ Kaassis M, Oberti F, Burtin P, Boyer J. Argon plasma coagulation for the treatment of hemorrhagic radiation proctitis. Endoscopy 2000; 32: 673-676

${ }^{3}$ Focke G, Seidl C, Grouls V. Treatment of watermelon stomach (GAVE syndrome) with endoscopic argon plasma coagulation (APC). A new therapy approach. Leber Magen Darm 1996; 26: 257-259

${ }^{4}$ Morrow JB, Dumot JA, Vargo JJ. Radiation-induced hemorrhagic carditis treated with argon plasma coagulator. Gastrointest Endosc 2000; 51: $498-$ 499

\section{Corresponding Author}

\section{S. Corbinais, M.D.}

Service des Maladies de l'Appareil Digestif CHRU Pontchaillou

Rue Henri Le Guilloux

35033 Rennes cedex 09

France

Fax: $\quad$ +33-299-284189

E-mail: stephcorbinais@yahoo.fr 